\title{
Effect of various growth media upon survival during storage of freeze-dried Enterococcus faecalis and Enterococcus durans
}

\author{
A.S. Carvalho', J. Silva' ${ }^{1}$, P. Ho ${ }^{1,2}$, P. Teixeira ${ }^{1}$, F.X. Malcata1 and P. Gibbs ${ }^{1}$ \\ ${ }^{1}$ Escola Superior de Biotecnologia, Universidade Católica Portuguesa, Porto, Portugal, and ${ }^{2}$ Departamento de Ciências de Engenharia \\ e Tecnologia, Escola Superior de Tecnologia e Gestão, Instituto Politécnico de Viana do Castelo, Viana do Castelo, Portugal
}

\section{ABSTRACT}

A.S. CARVALHO, J. SILVA, P. HO, P. TEIXEIRA, F.X. MALCATA AND P. GIBBS. 2003.

Aims: The effects of three different growth media (MRS, M17 and Lee's) on survival during freeze-drying and subsequent storage of six strains of Enterococcus faecalis and two strains of $E$. durans were investigated.

Methods and Results: Distinct Enterococcus spp. strains were grown on M17, MRS and Lee's broth, freeze-dried and stored at $20^{\circ} \mathrm{C}$ in air under darkness. At regular intervals throughout storage, freeze-dried samples were rehydrated and then plated on M17 agar.

Conclusions: A higher survival rate during storage of dried E. durans was obtained when growth occurred in MRS. The same effect was not observed, however, for the majority of E. faecalis strains, which clearly survived better in the dried state when this organism had been grown in M17 or Lee's medium.

Significance and Impact of Study: The survival of the dried Enterococcus spp. tested during storage was shown to be strain-specific and dependent on the growth medium.

Keywords: Enterococcus spp., growth medium, preservation, viability.

\section{INTRODUCTION}

There is an increasing demand for artisanal dairy products, which is partly due to the uniqueness of such foods; in which wild strains (adventitious in raw milk) grow actively and hence contribute to the final organoleptic characteristics of such cheeses (Suzzi et al. 2000). Enterococci play a major role in ripening and aroma development in several cheeses. A few strains also possess probiotic properties (Klein et al. 1998), and in general they represent an important component of the bacterial flora of dairy products manufactured from raw milk (Morea et al. 1999; Durlu-Ozkaya et al. 2001), particularly in southern Europe (Franz et al. 1999). Characterization of the microflora of traditional cheeses may not only shed light on the specific mechanisms of ripening,

Correspondence to: P. Teixeira, Escola Superior de Biotecnologia, Universidade Catolica Portuguesa, Rua Dr. António Bernardino de Almeida, P-4200-072 Porto, Portugal (e-mail: paula@esb.ucp.pt). but also contribute to their preservation via inclusion in tailor-made starter and non-starter cultures. These cultures will eventually lead to standardization of product quality and safety, without hampering it's organoleptic uniqueness. However, the industrial exploitation of lactic acid bacteria $(\mathrm{LAB})$ as starter cultures (with a potential probiotic role) is dependent on preservation technologies, which are required to guarantee delivery of stable cultures in terms of viability and metabolic functions (Pamfedt and Hähn-Hagerdal 2000). Freeze-drying is often used for preservation and storage of biological samples; however, it brings about undesirable side-effects, such as denaturation of sensitive proteins and decreased viability of many cell types (Leslie et al. 1995).

The objectives of this work were to investigate the effects of three commonly used growth media upon the survival during freeze-drying, and subsequent storage of selected native strains of Enterococcus faecalis and E. durans. 


\section{MATERIALS AND METHODS}

\section{Media preparation}

MRS medium (LAB M, Bury, UK), initially proposed by de Man et al. (1960), and M17 medium (Merck, Frankfurt, Germany), initially proposed by Terzaghi and Sandine (1975), were prepared according to the manufacturer's instructions. Lee's medium was prepared from individual ingredients in our laboratory, following the original recipe by Lee et al. (1974). The compositions of the three media are given in Table 1.

\section{Bacterial strains}

Strains of E. faecalis (EF1, EF2, EF3, EF4, EF5 and EF6) and $E$. durans (ED1 and ED2) had been isolated from Portuguese hard cheeses, and characterized following Durlu-Ozkaya et al. (2001). The original reference cultures were maintained in cryogenic storage at $-80^{\circ} \mathrm{C}$ on glass beads.

\section{Culture conditions}

Working cultures were maintained as slopes on M17 agar, stored at $4^{\circ} \mathrm{C}$ and subcultured every month. Slopes were in turn prepared from cultures grown on M17 broth and incubated at $37{ }^{\circ} \mathrm{C}$ for $24 \mathrm{~h} ; \mathrm{M} 17$ broth was inoculated from the M17 agar slopes and again incubated at $37^{\circ} \mathrm{C}$ for $24 \mathrm{~h}$. This culture was then used to inoculate, at $1 \%(\mathrm{v} / \mathrm{v}), \mathrm{MRS}$, M17 and Lee's broths, which were then incubated at $37^{\circ} \mathrm{C}$

Table 1 Composition of the media used for growth of Enterococcus faecalis and E. durans

\begin{tabular}{llcl} 
Component & MRS $\left(\mathrm{g} \mathrm{l}^{-1}\right)$ & M17 $\left(\mathrm{g} \mathrm{l}^{-1}\right)$ & Lee's $\left(\mathrm{g} \mathrm{l}^{-1}\right)$ \\
\hline Polypeptone & 10 & - & - \\
Peptone soymeal & - & $5 \cdot 0$ & - \\
Peptone from meat & - & $2 \cdot 5$ & - \\
Peptone from casein & - & $2 \cdot 5$ & - \\
Tryptone & - & - & 10 \\
Meat extract & 10 & 5 & - \\
Yeast extract & 5 & $2 \cdot 5$ & 10 \\
Glucose & 20 & - & - \\
Lactose & - & $5 \cdot 0$ & $5 \cdot 0$ \\
Sucrose & - & - & $5 \cdot 0$ \\
Na- $\beta$-glycerolphosphate & - & 19 & - \\
Dipotassium phosphate & $2 \cdot 0$ & - & $0 \cdot 5$ \\
Sodium acetate & $5 \cdot 0$ & - & - \\
Ammonium citrate & $2 \cdot 0$ & - & - \\
Tween 80 & $1 \cdot 08$ & - & - \\
Ascorbic acid & - & $0 \cdot 5$ & - \\
Magnesium sulphate & $0 \cdot 2$ & $0 \cdot 25$ & - \\
Manganese sulphate & $0 \cdot 05$ & - & -
\end{tabular}

for $24 \mathrm{~h}$. Cells were harvested by centrifugation at $7000 \times g$ for $10 \mathrm{~min}$ and washed twice with sterile Ringer's solution (LAB M). Cells were suspended in sterile skim milk containing $11 \%(\mathrm{w} / \mathrm{v})$ solids (LAB M), allowed to equilibrate for $1 \mathrm{~h}$ at room temperature $\left(20^{\circ} \mathrm{C}\right)$ and then frozen $\left(-80{ }^{\circ} \mathrm{C}\right.$ for $\left.24 \mathrm{~h}\right)$ in plastic tubes. Each experiment was repeated three times.

\section{Freeze-drying and storage}

Samples of $20 \mathrm{ml}$ were desiccated under vacuum $(50 \mathrm{mTorr}$ for $48 \mathrm{~h}$ ) in a freeze-drier (Martin Christ, Osterad am Harz, Germany), at room temperature $\left(20^{\circ} \mathrm{C}\right)$; the condenser was cooled at $-55^{\circ} \mathrm{C}$. Dried cells were stored in hermetic closed containers at $20^{\circ} \mathrm{C}$ in air and maintained in the darkness.

\section{Enumeration of survivors}

At regular intervals throughout storage, freeze-dried samples were rehydrated to the original volume with sterile deionized water; suitable dilutions were then plated on M17 agar by the drop count technique (Miles and Misra 1938). Three drops $(20 \mu \mathrm{l}$ each) of the suitable dilution were placed on each of three separate plates, which were examined after incubation at $37{ }^{\circ} \mathrm{C}$ for $48 \mathrm{~h}$.

\section{Statistical analysis}

The mean values of three replicated viable counts, right after freeze-drying and at regular intervals during storage, were subject to analysis of variance (ANOVA) using the statistical software R (Ihaka and Gentleman 1996), at the 5\% level of significance. Multiple comparison of treatment mean values, using $95 \%$ confidence intervals, was done using Tukey's honestly significant difference, and the results plotted using Trellis display so as to grasp important interactions between factors (Becker et al. 1996).

\section{RESULTS}

Four factors were considered with regard to viability: experimental replication, strain, growth medium and storage time. The ANOVA results encompassing these factors indicated that all main effects, some two-way interactions and the three- and four-way interactions were statistically significant (Table 2). The survival of freeze-dried Enterococcus spp. during storage (but not during freeze-drying) was shown to be dependent on the growth medium $(P<0 \cdot 0001)$ and on the strain $(P<0 \cdot 0001)$. The influence of the growth medium on survival during storage depended on the specific strain being tested, because the corresponding two-way interaction was significant $(P<0 \cdot 0001)$. As there were significant interactions between factors (Table 2), the effects 
Table 2 ANOVA of the effects of different growth media on survival during freezedrying and subsequent storage, of several strains of Enterococcus faecalis and E. durans

\begin{tabular}{|c|c|c|c|c|c|}
\hline Source of variation & $\begin{array}{l}\text { Degrees of } \\
\text { freedom }\end{array}$ & $\begin{array}{l}\text { Sum of } \\
\text { squares }\end{array}$ & $\begin{array}{l}\text { Mean } \\
\text { square }\end{array}$ & $F$-ratio & $P$-value \\
\hline Experimental replication (ER) & 2 & $0 \cdot 05$ & $0 \cdot 03$ & $4 \cdot 12$ & $1.6 \times 10^{-2^{*}}$ \\
\hline Strain $(S)$ & 7 & $30 \cdot 38$ & $4 \cdot 34$ & $664 \cdot 92$ & $<2 \cdot 2 \times 10^{-16^{* * *}}$ \\
\hline Growth medium (GM) & 2 & $26 \cdot 70$ & $13 \cdot 35$ & $2045 \cdot 18$ & $<2 \cdot 2 \times 10^{-16^{* * *}}$ \\
\hline Storage time (ST) & 8 & $844 \cdot 89$ & $105 \cdot 61$ & $16178 \cdot 78$ & $<2 \cdot 2 \times 10^{-16^{* * *}}$ \\
\hline $\mathrm{ER} \times \mathrm{S}$ & 14 & $0 \cdot 13$ & $0 \cdot 01$ & $1 \cdot 41$ & $0 \cdot 142$ \\
\hline $\mathrm{ER} \times \mathrm{GM}$ & 4 & $0 \cdot 03$ & $0 \cdot 01$ & $1 \cdot 32$ & $0 \cdot 259$ \\
\hline $\mathrm{ER} \times \mathrm{ST}$ & 16 & $0 \cdot 70$ & $0 \cdot 04$ & $6 \cdot 72$ & $6.8 \times 10^{-15^{* * *}}$ \\
\hline $\mathrm{S} \times \mathrm{GM}$ & 14 & $118 \cdot 34$ & $8 \cdot 45$ & $1294 \cdot 90$ & $<2 \cdot 2 \times 10^{-16^{* * *}}$ \\
\hline $\mathrm{S} \times \mathrm{ST}$ & 56 & $42 \cdot 88$ & $0 \cdot 77$ & $117 \cdot 31$ & $<2 \cdot 2 \times 10^{-16^{* * *}}$ \\
\hline $\mathrm{GM} \times \mathrm{T}$ & 16 & $14 \cdot 22$ & $0 \cdot 89$ & 136.11 & $<2 \cdot 2 \times 10^{-16^{* * *}}$ \\
\hline $\mathrm{ER} \times \mathrm{S} \times \mathrm{GM}$ & 28 & $0 \cdot 28$ & $0 \cdot 01$ & 1.53 & $3 \cdot 7 \times 10^{-2 *}$ \\
\hline $\mathrm{ER} \times \mathrm{S} \times \mathrm{ST}$ & 112 & $0 \cdot 62$ & $0 \cdot 01$ & $0 \cdot 85$ & $0 \cdot 861$ \\
\hline $\mathrm{ER} \times \mathrm{GM} \times \mathrm{ST}$ & 32 & $0 \cdot 21$ & $0 \cdot 01$ & $1 \cdot 02$ & 0.435 \\
\hline $\mathrm{S} \times \mathrm{GM} \times \mathrm{ST}$ & 112 & $95 \cdot 61$ & $0 \cdot 85$ & $130 \cdot 78$ & $<2 \cdot 2 \times 10^{-16^{* * *}}$ \\
\hline $\mathrm{ER} \times \mathrm{S} \times \mathrm{GM} \times \mathrm{ST}$ & 224 & $2 \cdot 07$ & $0 \cdot 01$ & $1 \cdot 41$ & $<1.9 \times 10^{-4^{* * *}}$ \\
\hline Residuals & 1296 & $8 \cdot 46$ & $0 \cdot 01$ & & \\
\hline
\end{tabular}

on survival of different strains during storage could not be estimated only from the treatment mean values. Due to the complexity of such analysis (which consisted of comparing the differences between each strain for every growth medium in three replicated experiments), and as there were interactions between factors, the best way to visualize those effects was to plot all combinations using a Trellis display (Fig. 1).

All strains tested underwent decrease in viability to some extent during dehydration, and a greater (but variable) decrease during storage. Enterococcus durans strains ED1 and ED2 clearly survived better in the dried state when cells had been grown in MRS. By the end of the storage period, there were no significant differences between the survival of ED1 and ED2 on Lee's and M17 media. During the period tested, the survival of E. faecalis strain EF1 during storage was not dependent on the growth medium used; E. faecalis strains EF3 and EF6 exhibited significantly higher survival rates during storage in dried form when the growth medium was M17. There were no significant differences between survival on Lee's and MRS media for strain EF3; however, in two of the experiments, strain EF6 survived better in Lee's than in MRS medium. Lee's and M17 would apparently be the best media for growth of strain EF5 if the objective function were maintenance of high viability during storage. A similar conclusion was possible for the strain EF4, except that there were no significant differences in survival in Lee's and MRS media. The highest viability during storage in the dried state for strain EF2 was attained when growth was in Lee's medium.

Measurements tabulated in Table 3 indicate that the final $\mathrm{pH}$ was higher (by $c a \cdot 1 \cdot 0 \mathrm{pH}$ unit) when growth was in M17 than in MRS or Lee's media.

\section{DISCUSSION}

Our research effort provided evidence of the impact of the growth medium on viability throughout storage of dried Enterococcus spp. Various studies (Leslie et al. 1995; Linders et al. 1997a,b; Abadias et al. 2001) have been carried out to evaluate the efficacy of different components added to the drying medium upon survival of microorganisms during drying and subsequent storage; our results showed, in addition, that the growth medium is a critical parameter, which is more likely to play a role upon survival following freeze-drying. The mechanisms underlying the protection afforded by the various media tested are rather complex, and the results of previous studies do not allow final conclusions to be drawn on the mode of action of those media. Nevertheless, when taking into account the compositions of the three media, tentative reasonings may be proposed.

Several factors have been identified which could affect the protection provided by the various media (e.g. carbohydrate sources, manganese sulphate, Tween 80 and ascorbic acid). The presence or absence, as well as the different concentrations of undefined components (e.g. peptones, tryptone, meat and yeast extract) might fulfil some requirements and lead to accumulation of different compounds, and would thus be responsible for the distinct survival behaviours observed. For instance, meat extract and yeast extract are the main sources of carnitine and betaine, respectively, some of the most important compatible solutes found in LAB; hence, accumulation of these solutes will promote survival of bacteria subject to drying (Kets and de Bont 1994; Kets et al. 1996). 


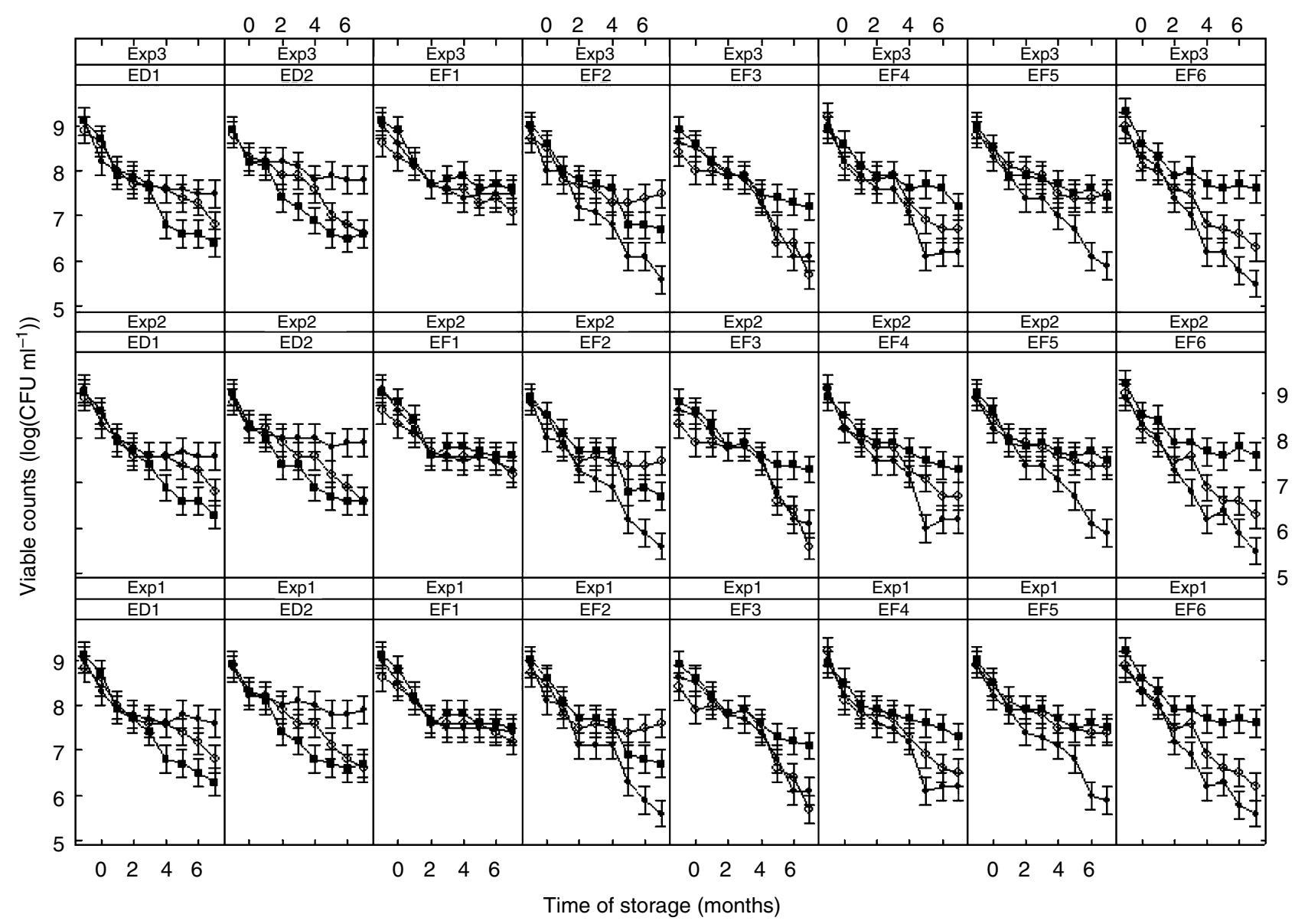

Fig. 1 Effect of various growth media: MRS $(\bullet), \operatorname{M17}(\boldsymbol{\square})$ and Lee's $(\bigcirc)$ on survival during freeze-drying and subsequent storage, of several strains of Enterococcus faecalis and E. durans. Bars represent the $95 \%$ confidence intervals of treatment mean values

\begin{tabular}{|c|c|c|c|c|c|c|}
\hline & \multicolumn{2}{|c|}{ MRS } & \multicolumn{2}{|c|}{ M17 } & \multicolumn{2}{|c|}{ Lee's } \\
\hline & $\mathrm{pH}_{\mathrm{i}}$ & $\mathrm{pH}_{\mathrm{f}}$ & $\mathrm{pH}_{\mathrm{i}}$ & $\mathrm{pH}_{\mathrm{f}}$ & $\mathrm{pH}_{\mathrm{i}}$ & $\mathrm{pH}_{\mathrm{f}}$ \\
\hline EF1 & $6 \cdot 6$ & $4 \cdot 4$ & $7 \cdot 4$ & $5 \cdot 4$ & $7 \cdot 2$ & $4 \cdot 4$ \\
\hline EF2 & $6 \cdot 6$ & $4 \cdot 5$ & $7 \cdot 4$ & $5 \cdot 4$ & $7 \cdot 2$ & 4.5 \\
\hline EF3 & $6 \cdot 6$ & $4 \cdot 5$ & $7 \cdot 4$ & 5.5 & $7 \cdot 2$ & 4.5 \\
\hline $\mathrm{EF} 4$ & $6 \cdot 6$ & $4 \cdot 6$ & $7 \cdot 4$ & 5.5 & $7 \cdot 2$ & $4 \cdot 4$ \\
\hline EF5 & 6.6 & $4 \cdot 7$ & $7 \cdot 4$ & 5.5 & $7 \cdot 2$ & $4 \cdot 7$ \\
\hline EF6 & $6 \cdot 6$ & $4 \cdot 6$ & $7 \cdot 4$ & $5 \cdot 5$ & $7 \cdot 2$ & $4 \cdot 4$ \\
\hline ED1 & $6 \cdot 6$ & $4 \cdot 4$ & $7 \cdot 4$ & 5.5 & $7 \cdot 2$ & $4 \cdot 2$ \\
\hline ED2 & $6 \cdot 6$ & $4 \cdot 4$ & $7 \cdot 4$ & $5 \cdot 5$ & $7 \cdot 2$ & $4 \cdot 3$ \\
\hline
\end{tabular}

Table 3 Variation of $\mathrm{pH}$ brought about by growth of several strains of Enterococcus faecalis and E. durans in various media

$\mathrm{pH}_{\mathrm{i}}$ - initial $\mathrm{pH}$ of the medium.

$\mathrm{pH}_{\mathrm{f}}-$ final $\mathrm{pH}$ of the medium, after strain growth at $37^{\circ} \mathrm{C}$ for $24 \mathrm{~h}$.

In our studies, the strains of E. faecalis and E. durans were exposed to different components of the growth media, e.g. presence or absence of Tween 80 and ascorbic acid, which may yield different fatty acid profiles and different degrees of oxidation of membrane lipids in those microorganisms; such fatty acid composition and degree of oxidation seems to be related to survival of cells during freeze drying (Goldberg and Eschar 1977; Murga et al. 2000) and subsequent storage 
in the dried state (Castro et al. 1996; Teixeira et al. 1996). It has previously been described (Smittle et al. 1974; Goldberg and Eschar 1977; Kimoto et al. 2002) that culturing with Tween 80 changes the fatty acid composition of LAB cells, and that this change influences their subsequent resistance to other forms of stress. However, our studies are in agreement with Kimoto et al. (2002) who claimed that such modification on the fatty acid profile is strain-dependent. The addition of ascorbic acid to the drying medium had already been demonstrated to have a protective effect on spray-dried cell concentrates of Lactobacillus bulgaricus during storage (Teixeira et al. 1995).

Another possible explanation for the differences observed relates to the different carbon sources in the three media. Studies by Hofvendahl and Hahn-Hägerdal (2000) showed that other compounds are formed by homofermenters in addition to lactic acid, during growth on sugars other than glucose. It is therefore possible that the different chemicals produced during fermentation of sugars might be responsible for the distinct survival behaviours during storage of freeze-dried E. faecalis and E. durans. This hypothesis is corroborated by the different final $\mathrm{pH}$ values achieved in the media tested.

Our findings also back up an alternative explanation. Acid shock or adaptation thereto may yield cells that exhibit alternative physiological states, and hence potentially different tolerances to other stresses (Abee and Wouters 1999). Previous studies (Giard et al. 2000) have indeed shown that starving E. faecalis, caused by glucose exhaustion, results in development of a multiresistant state that protects the starved cells from other stresses. However, Rince et al. (2000) reported that adaptation of E. faecalis to acidic $\mathrm{pH}$ resulted in only a small effect by other challenges. In our studies, adaptation to low $\mathrm{pH}$ seems to produce cells with different sensitivities to further stress (e.g. storage in the dried state). Owing to such a heterogeneous behaviour, no conclusions can be drawn pertaining to the relationship between $\mathrm{pH}$ adaptation and subsequent resistance in the dried state. It was also reported (Tourdot-Maréchal et al. 2000) that adaptation of Oenococcus oeni to acidic conditions had no effect on membrane fluidity, in contrast to other types of adaptations.

Of the three media tested in this study, only MRS contained manganese. Note that for most LAB deprived of Mn (II), sensitivity to oxygen is increased as (i) it may substitute superoxide dismutase (SOD) or (ii) it is essential for SOD activity, hence protecting the cell against the direct and indirect toxic effects of reactive oxygen species (Archibald and Fridovich 1981); such species have numerous cellular targets, e.g. DNA and membrane, thus leading to strand breaks and peroxidation of lipids, respectively (Flahaut et al. 1998). A manganese-dependent SOD was identified in various enterococcal strains (Poyart et al. 2000) and the gene encoding for Mn-dependent SOD was different for the two enterococcal species used in these studies.

Our data indicate that distinct strains can differ in their behaviour during storage in the dried state, but the reasoning behind that realization is unclear. It was suggested (O'Callaghan and Condon 2000) that gene transfer between strains may have led to differences in phenotype between distinct Lactococcus lactis strains. Although cause and effect mechanisms require further investigation, our results already point to the importance of the growth medium on the survival during storage of freeze-dried enterococcal strains. It is also important to realize that, for each $\mathrm{LAB}$ strain of interest, the influence(s) of growth conditions, and probably the composition of the drying medium on the survival in the dried state, are specific for that strain.

\section{ACKNOWLEDGEMENTS}

This work received financial support through project PRAXIS/P/BIO/12147/1998 (FCT, Portugal), co-ordinated by P. Teixeira and P. Gibbs. Financial support for authors A.S. Carvalho and J. Silva was provided by $\mathrm{PhD}$ fellowships PRAXIS XXI/BD/18152/98 and PRAXIS XXI/BD/197131/99, respectively (FCT).

\section{REFERENCES}

Abadias, M., Benabarre, A., Teixidó, N., Usall, J. and Viñas, I. (2001) Effect of freeze-drying and protectants on viability of biocontrol yeast Candida sake. International Fournal of Food Microbiology 65, 173-182.

Abee, T. and Wouters, J.A. (1999) Microbial stress response in minimal processing. International fournal of Food Microbiology 50, 65-91.

Archibald, F.S. and Fridovich, I. (1981) Manganese, superoxide dismutase, and oxygen tolerance in some lactic acid bacteria. Fournal of Bacteriology 146, 928-936.

Becker, R.A., Cleveland, W.S. and Shyu, M.-J. (1996) The visual design and control trellis display. Fournal of Computational and Graphical Statistics 5, 123-155.

Castro, H.P., Teixeira, P.M. and Kirby, R. (1996) Changes in the membrane of Lactobacillus bulgaricus during storage following freezedrying. Biotechnology Letters 18, 99-104.

de Man, J.C., Rogosa, M. and Sharpe, M.E. (1960) A medium for the cultivation of lactobacilli. Fournal of Applied Bacteriology 23, 130135.

Durlu-Ozkaya, F., Xanthopoulos, V., Tunaii, N. and LitopoulouTzanetaki, E. (2001) Technologically important properties of lactic acid bacteria isolates from Beyaz cheese made from raw ewes'milk. Journal of Applied Microbiology 91, 861-870.

Flahaut, S., Laplace, J.-M., Frère, J. and Aufray, Y. (1998) The oxidative stress response in Enterococcus faecalis: relationship between $\mathrm{H}_{2} \mathrm{O}_{2}$ tolerance and $\mathrm{H}_{2} \mathrm{O}_{2}$ stress. Letters in Applied Microbiology 26, 259-264. 
Franz, C., Holzapfel, W.H. and Stiles, M.E. (1999) Enterococci at the crossroads of food safety? International Fournal of Food Microbiology $47,1-24$.

Giard, J.F., Rince, A., Capiaux, H., Aufray, Y. and Hartke, A. (2000) Inactivation of the stress- and starvation-inducible $g l s 24$ operon has a pleiotrophic effect on cell morphology, stress sensitivity, and gene expression in Enterococcus faecalis. Fournal of Bacteriology 182, 4512 4520 .

Goldberg, I. and Eschar, L. (1977) Stability of lactic acid bacteria to freezing as related to their fatty acid composition. Fournal of Dairy Science 33, 489-496.

Hofvendahl, K. and Hahn-Hägerdal, B. (2000) Factors affecting the fermentative lactic acid production from renewable resources. Enzyme and Microbial Technology 26, 87-107.

Ihaka, R. and Gentleman, R. (1996) R: a language for data analysis and graphics. Fournal of Computational and Graphical Statistics 5, 299 314.

Kets, E.P.W. and de Bont, J.A.M. (1994) Protective effect of betaine on survival of Lactobacillus plantarum subjected to drying. FEMS Microbiology Letters 116, 251-256.

Kets, E.P.W., Galinski, E.A., de Wit, M., de Bont, J.A.M. and Heipieper, H.J. (1996) Mannitol, a novel bacteria compatible solute on Pseudomonas putida S12. Fournal of Bacteriology 178, 6665-6670.

Kimoto, H., Ohmomo, S. and Okamoto, T. (2002) Enhancement of bile tolerance in lactococci by Tween 80. Fournal of Applied Microbiology 92, 41-46.

Klein, G., Pack, A., Bonaparte, C. and Reuter, G. (1998) Taxonomy and physiology of probiotic lactic acid bacteria. International fournal of Food Microbiology 41, 103-125.

Lee, S.Y., Vedamuthu, E.R. and Washam, C.J. (1974) An agar medium for the differential enumeration of yoghurt starter bacteria. Fournal of Milk and Food Technology 37, 272.

Leslie, S.B., Israeli, E., Lighthart, B., Crowe, J.H. and Crowe, L.M. (1995) Trehalose and sucrose protect both membranes and proteins in intact bacteria during drying. Applied and Environmental Microbiology 61, 3592-3597.

Linders, L.J.M., Wolkers, W.F., Hoekstra, F.A. and van't Riet, K. (1997a) Effect of added carbohydrates on membrane phase behaviour and survival of dried Lactobacillus plantarum. Cryobiology 35, 31-40.

Linders, L.J.M., de Jong, G.I.W., Meerdink, G. and van't Riet, K. (1997b) Carbohydrates and the dehydration inactivation of Lactobacillus plantarum: the role of moisture distribution and water activity. Fournal of Food Engineering 31, 237-250.
Miles, A.A. and Misra, S.S. (1938) The estimation of the bactericidal power of blood. Fournal of Hygiene 38, 732-749.

Morea, M., Baruzzi, F. and Cocconcelli, P.S. (1999) Molecular and physiological characterization of dominant bacterial populations in traditional Mozarella cheese processing. Fournal of Applied Microbiology 87, 574-582.

Murga, M.L.F., Cabrera, G.M., Font de Valdez, G., Disalvo, A. and Seides, A.M. (2000) Influence of growth temperature on cryotolerance and lipid composition of Lactobacillus acidophilus. Fournal of Applied Microbiology 88, 342-348.

O'Callaghan, J. and Condon, S. (2000) Growth of Lactococcus lactis strains at low water activity: correlation with the ability to accumulate glycine and betaine. International Fournal of Food Microbiology 55, 127-131.

Pamfedt, J. and Hähn-Hagerdal, B. (2000) Influence of culture $\mathrm{pH}$ on survival of Lactobacillus reuteri subjected to freeze-drying. International Journal of Food Microbiology 47, 1-24.

Poyart, C., Quesnes, G. and Trieu-Cout, P. (2000) Sequencing the gene encoding manganese-dependent superoxide dismutase for rapid species identification of enterococci. Fournal of Clinical Microbiology 38, 415-418.

Rince, A., Flahaut, S. and Auffray, Y. (2000) Identification of general stress genes in Enterococcus faecalis. International fournal of Food Microbiology 55, 127-131.

Smittle, R.B., Gilliland, S.E., Speck, M.L. and Walter, W.M. (1974) Relationship of cellular fatty acid composition to survival of Lactobacillus bulgaricus in liquid nitrogen. Applied Microbiology 27, 738-743.

Suzzi, G., Caruso, M., Gordini, F., Lombardi, A., Vannini, L., Guerzoni, M.E., Andrighetto, C. and Lanorte, M.T. (2000) A survey of the enterococci isolated from an artisanal Italian goat's cheese (semicotto caprino). Fournal of Applied Microbiology 89, 267274.

Teixeira, P., Castro, H., Malcata, F.X. and Kirby, R. (1995) Survival of Lactobacillus delbrueckii ssp. bulgaricus following spray-drying. Fournal of Dairy Science 78, 1025-1031.

Teixeira, P., Castro, H. and Kirby, R. (1996) Evidence of membrane lipid oxidation of spray-dried Lactobacillus bulgaricus during storage. Letters in Applied Microbiology 22, 34-38.

Terzaghi, B.E. and Sandine, W.E. (1975) Improved medium for lactic streptococci and their bacteriophages. Applied and Environmental Microbiology 29, 807-813.

Tourdot-Maréchal, R., Gaboriau, D., Beney, L. and Diviés, C. (2000) Membrane fluidity of stressed cells of Oenococcus oeni. International Journal of Food Microbiology 55, 127-131. 